•保护论坛・

\title{
推动中国企业参与《生物多样性公约》 全球伙伴关系的机制建设
}

\author{
赵 阳 ${ }^{1}$ 温源远 ${ }^{1,2 *}$ 杨礼荣 ${ }^{1}$ 李宏涛 \\ 1 (生态环境部环境保护对外合作中心, 北京 100035) \\ 2 (北京师范大学环境学院, 北京 100875)
}

\begin{abstract}
摘要: 党的十九大首次提出了中国要成为全球生态文明建设引领者的新要求。生物多样性保护是中国生态文明建 设和全球生态文明建设的重要内容, 也是构建人与自然生命共同体、人类命运共同体、清洁美丽世界的集中体现。 本文系统总结了推动 《生物多样性公约》倡导的“企业与生物多样性全球伙伴关系” (GPBB)的主要国际经验, 提出 了中国推动落实“中国企业与生物多样性伙伴关系”倡议(简称CBBP)的政策建议, 为中国政府更好地引导企业参 与, 拰动社会资源合力加强生物多样性保护提供参考。通过分析德国、印度、加拿大、秘鲁、澳大利亚、南非、 日本和韩国构建企业参与GPBB的实践, 发现各国经验主要有以下特点: (1)政府作用重要且方式多样, 或提供管 理、或提供资金或实物等; (2)组织方式多样, 常见的为组建跨部门的决策机构并下设秘书组; (3)成员加入, 一般需 要签署协约, 有的偏重特定行业, 有的重视机构会员; (4)在服务上, 政府一般提供法律政策解读、知识信息传播、 政策指引等服务; (5)在资金来源上，有的主要靠缴纳会费，有的包括实物捐赠、志愿服务、PPP (公私合营)项目合 作等方式。各国经验的主要启示有: (1)根据论坛会议沟通和实际工作交流, 大量企业表现出参与生物多样性伙伴 关系倡议的积极意愿; (2)推动企业参与的国际资源网络已基本建立; (3)受限于规模和资金, 绝大多数企业的参与 需要本国政府更为有力的引导和支持。2015年, 中国正式加入GPBB。截至目前, 虽然中国已开展了许多推动GPBB 的相关工作, 但仍然存在和面临许多问题与挑战: (1)由于中国倡议CBBP相关文件仍未通过审批, 因此, 尽管根据 调研已有许多企业非常有意愿成为中国伙伴关系成员单位, 但仍无章可循, 无法加入; (2)中国尚未建立健全的推 动CBBP倡议行动的组织模式和资金机制; (3) 《生物多样性公约》第15次缔约方大会将于2020年在北京召开, 这对 中国在促进CBBP的管理运行也提出更高和更为紧迫的要求。对此, 本文建议CBBP倡议可实施“两步走”战略: (1) 成立并发起CBBP联盟倡议; (2)加大国际公约建设和国家履约谈判支持。
\end{abstract}

关键词: 生物多样性保护; 国际经验; 全球伙伴关系; 生物多样性公约; 企业参与

\section{Learning from international experience to promote the Global Partnership between Business and Biodiversity (GPBB) in China}

Yang Zhao ${ }^{1}$, Yuanyuan Wen ${ }^{1,2^{*}}$, Lirong Yang ${ }^{1}$, Hongtao $\mathrm{Li}^{1}$

1 Foreign Economic Corporation Office, Ministry of Ecology and Environment of the People's Republic of China, Beijing 100035

2 School of Environment, Beijing Normal University, Beijing 100875

\begin{abstract}
The 19th National Congress of the Communist Party of China put forward for the first time a new requirement that China should spearhead the construction of ecological civilization on global scale, of which biodiversity protection is an integral part. This paper systematically summarizes the major international experiences in promoting the Global Partnership for Business and Biodiversity (GPBB) advocated by the Convention on Biological Diversity, and gives policy proposals for China to promote the GPBB (or China Business and Biodiversity Partnership, CBBP). By analyzing GPBB practices in Germany, India, Canada, Peru, Australia, South Africa, Japan and South Korea, we find the main experience of these countries as
\end{abstract}


follows: (1) the governments have important and varied roles, including management and providing funds or goods; (2) the patterns of organization are diverse, but usually they set up cross department decision-making bodies and secretarial offices; (3) membership generally requires signing agreements; some agreements focus on specific industries, some accord importance to institutional members; (4) the government generally provides legal and policy interpretation, knowledge and information dissemination, policy guidance and other services; (5) regarding funding, some mainly rely on the collection of membership dues while others rely on donations in kind or voluntary service, and some rely on PPP projects. We also draw the following conclusions: (1) a large number of enterprises are motivated and willing to participate in the Biodiversity Partnership Initiative; (2) the international resource network for promoting enterprise participation has been established; (3) limited by scale and capital, the participation of the vast enterprises requires more guidance and support of government. In 2015, China formally joined the GPBB. Although China has carried out several related activities to promote the GPBB, it still faces many challenges. First of all, the relevant documents have not been approved. Therefore, although many enterprises are willing to partner with China, there is a need to establish rules to follow. Secondly, China has not yet established a sound organizational mode and financial mechanism to promote GPBB. Finally, the 15th conference of the parties to the Convention on Biological Diversity (CBD) will be held in Beijing in 2020, which creates an urgent need to manage China's partnership for business and biodiversity. In this regard, this paper suggests that the China Business and Biodiversity Partnership (CBBP) initiative should implement the two step strategy: (1) establish and launch the CBBP alliance initiative, and (2) increase the support of international conventions and state performance negotiations.

Key words: biodiversity; international experience; global partnership; Convention on Biological Diversity (CBD); business participation

中国共产党的十九大报告作出了中国成为全 球生态文明建设的重要参与者、贡献者和引领者的 重要判断。《生物多样性公约》(以下简称《公约》) 是国际社会协力保护生物多样性最重要的公约, 也 是中国引领全球生态文明建设的重要平台。生物多 样性保护与可持续利用涉及多元利益相关方, 需要 多方合力解决。企业是开发和利用生物多样性资源 的主体, 也是实现生物多样性可持续发展的重要推 动力量, 推动 《公约》倡导的“企业与生物多样性全 球伙伴关系” (Global Partnership on Business and Biodiversity, GPBB)意义重大。本文系统总结了推动 落实GPBB倡议的主要国际经验, 提出了中国推动 落实中国企业与生物多样性伙伴关系 (China Business and Biodiversity Partnership, CBBP)倡议的 政策建议, 为中国政府如何更好引导企业参与, 利 用社会资源加强生物多样性保护提供参考。

\section{1 国际社会推动GPBB的主要进展}

联合国于1992年通过了《生物多样性公约》。 《公约》缔约方大会又相继通过了相关决议, 明确 了企业参与的重要意义和实现方法。继1996年《公 约》缔约方大会第三次会议(COP-3)首次提出企业
(私营部门)参与生物多样性的概念后, COP-5将企 业参与列入 《公约》议题, COP-6正式将企业参与纳 入 《公约》全球战略, COP-8首次将企业参与生物多 样性单独纳入 《公约》决议, COP-9拟定了《企业优 先行动框架(2008-2010年)》。根据2010年COP-10通 过的《企业界的参与》21号决议以及2012年COP-11 通过的《生物多样性促进消除贫困和发展》和《企 业界与生物多样性》决议要求, 2014年《公约》秘 书处成立了 GPBB，为国家和区域提供分享和对话 的平台, 为企业在决策和运营中纳入生物多样性提 供信息、知识、资源和解决方案，促进私营部门主 流化。第十二次《公约》大会决议《企业界的参与》 重申《公约》支持各国加入GPBB，同时强调企业贡 献《爱知目标》等国际议程的意义。目前已有 17 个 国家加入GPBB倡议以及3 个GPBB地区倡议(王爱 华等, 2015)。

\section{2 各国政府推进GPBB的实践情况}

各国推进GPBB的本国工作机制和名称各不相 同，如德国名为“好企业行为”倡议(Business in Good Company, BIGC), 印度名为“印度企业和生物多样 性倡议” (India Business and Biodiversity Initiative, 
IBBI), 中国名为CBBP。本文研究了相关工作较为 成熟有效的 6 个国家(德国、印度、加拿大、秘鲁、 澳大利亚与南非)的主要做法, 分别加以介绍。

\section{1 德国}

德国是探索推进企业参与生物多样性的先锋 国家，于2008年发起了名为“好企业行为” (Business in Good Company, BIGC)倡议。该倡议于2008年获 得联邦政府资金，直到2011年改为通过会员缴费、 捐赠和项目资金获得资金。BIGC拥有70家企业会员， 7名董事会成员全部来自企业, 每两年选举一次, 重点工作计划在每年一次的全体成员大会上讨论 通过。加入BIGC的公司须签署《领导者宣言》, 承 诺为一系列生物多样性保护目标做出贡献, 按 BIGC所开发的监测评估指标披露进展信息, 并缴 纳1,000-5,000欧元的会员费。目前50\%的BIGC运营 成本由会费负担。BIGC举办了一系列关于生态系统 服务、自然资本和水资源价值评估的培训研讨会, 并针对成员企业特定需求提供收费服务项目。

\section{2 印度}

印度在2014年发起了名为“印度企业和生物多 样性倡议” (India Business and Biodiversity Initiative, IBBI)。在2014年新德里举办的全球生物多样性日纪 念活动中, 由环境、森林和气候变化部批准和授权 印度工业联合会(CII)正式成立并发起该倡议, 由德 国国际合作机构(GIZ)提供技术支持。企业加入需签 署一份包括十项原则的《宣言》, 承诺企业内部任 命一名专员, 负责在环境管理体系中纳入生物多样 性指标、开展生态系统服务价值评估, 分析相关风 险与机会, 以及每两年公布相关信息等。IBBI通过 生物多样性评奖、价值核算和信息披露三个工作组 开展具体活动, 主要依托工业联合会下属的行业协 会和商会促进企业参与, 现有 40 个成员。

\section{3 加拿大}

加拿大成立了 “加拿大企业与生物多样性理事 会” (Canadian Business and Biodiversity Council, CBBC), 并由联邦政府与两个非政府组织 NatureServe Canada和Vale Canada共同出资。主要收入来 自根据企业规模收缴的会员费。董事会作为决策机 构, 由9名代表构成, 包括来自联邦政府、省级政 府、联合国环境规划署(UNEP)和科研单位各1人, 非政府组织 2 人以及 3 名企业代表, 是真正意义上的 跨部门伙伴关系。最近, CBBC制定与发布了《企业
与生物多样性保护指引》, 为在商业规划、运营和 决策中纳入相关议题提供了指导和建议。CBBC提 供了覆盖各行业的企业实践案例作为该指引的附 件以提供参考。此外, $\mathrm{CBBC}$ 提供的服务还包括编辑 简报和为采掘业行业协会举办系列培训研讨会等。

\section{4 秘鲁}

2014年，秘鲁环境部启动了名为“企业生物多 样性保护” (Biodiversidad y Empresas, ByE)的倡议, 旨在生物多样性和生态系统服务这一主题上, 构建 私营-公共部门(尤其是环境部)的对话平台。企业在 签署《利益宣言》后方被批准加入。ByE主要由两 个工作组通过开发、实施协同增效的项目来开展工 作。其中, 政府工作组是经环境部部长批准, 由 “自然资源战略发展部”及其下属两个部门“自然资 本评估、定价与金融总局”和“生物多样性总局”组成; 企业工作组则由19家企业和商会组成。政府组和企 业组共同推动在政府间合作中纳入试点企业以获 得项目资金，并为企业带来先进的管理、技术和经 验等。为更好地对接企业需求与政府项目，秘鲁倡 议还设立了最佳实践工具与指引、激励机制、就地 保护(保护地)和信息管理等主题小组, 每组由政府 组和企业组代表各一名牵头推进。

\section{5 澳大利亚}

2012年，澳大利亚国家银行在签署联合国可持 续发展大会“里约 +20 ” 《自然资本宣言》后，委托非 盈利社会机构“澳大利亚可持续商会” (SBA)发起成 立了“澳大利亚企业与生物多样性倡议” (Australian Business and Biodiversity Initiative, ABBI)。其指导 委员会是战略决策机构, 成员来自澳大利亚国家银 行、环境部与SBA, 已有约 150 个企业成员, 其中4 个银行成员最为活跃。ABBI主要关注生物多样性和 自然资本风险, 以及生物多样性适应气候变化的能 力等领域。目前还未实行收费，而是通过环保部捐 赠实物, SBA提供会员管理服务, 指导委志愿无偿 贡献时间而实现财务平衡。ABBI每年召开一次全体 论坛，分享信息并介绍国外最佳实践，并在不同伙 伴之间促进具体项目活动。

\section{6 南非}

经南非环境部批准, 濒危野生动物信托成立了 “南非国家生物多样性与企业网络” (National Biodiversity and Business Network, NBBN)。该信托 是一个包容性的组织，包括来自政府、保护组织、 
金融、房地产、交通基础设施、零售和快速消费品 以及采掘业的企业代表。NBBN主要成员来自矿业、 旅游和食品部门, 指导委成员有15-20名, 目前致 力于开发一套监测和评估指标。NBBN将企业成员 进行了分级，具体包括：合作伙伴(缴纳会费)、支持 伙伴(捐赠实物或具体贡献)和一般成员(提交企业 详细资料和加入申请, 被纳入NBBN数据库中)。 NBBN每年召开年度大会、举办一系列培训研讨会, 并分享相关立法、政策、投资与激励机制的信息。

\section{7 日本}

2008年，日本14个公司共同启动“日本企业与 生物多样性倡议” (Japan Business Initiative for Biodiversity, JBIB), 并于 2014年加入GPBB, 目前 成员数量已发展到 55 个, 全部是本土企业。JBIB的 特点为: 完全市场化运作、集体决策、成员贡献、 成本分摊、自负盈亏。组织架构包括由兼职人员组 成的秘书处和由活跃代表构成的委员会。主席来自 企业并经选举产生。企业成员每年缴纳3,000美元, $50 \%$ 用于秘书处日常运行，另外 $50 \%$ 用于活动预算。

最近JBIB启动了 “Challenge 2020行动”, 支持 企业核算其对生物多样性的依赖和因生物多样性 下降受到的影响, 以及采取具体措施削减生态足 迹。日常工作由秘书处协调工作组开展, 重点包括: 技术支持、品牌宣传、政策对话和环境教育等。

\section{8 韩国}

经环境部批准，韩国可持续发展工商理事会与 韩国生物技术产业组织于2016年共同创立了“企业 与生物多样性平台” (Biz N Biodiversity Platform, BNBP), 旨在应对 《名古屋议定书》的要求, 保护 国内基因资源, 促进采购、生产与流通中遗传物质 的可持续利用。BNBP推动相关产业的龙头企业与 政府部门基于PPP合作, BNBP成员企业的参与实践 包括：可持续利用生物多样性资源、惠益分享、应 对《名古屋议定书》的要求、科学研究、海洋保护 应用创新技术、科普读物、知识普及和公众参与等。

\section{3 各国推进GPBB的主要特点}

综上, 从政府职能、组织架构、成员加入、服 务体系、财务平衡和未来挑战等维度看, 不同国家 推动GPBB的模式具有不同特点。

\section{1 政府职能}

各国倡议中, 政府作用都很重要, 但发挥作用
的方式不尽相同。主要包括：直接管理(秘鲁)、资 金提供(德国)、实物赠与(澳大利亚)、部门合作(韩 国)、外资项目(秘鲁)、认证批复(南非)等不同方式。

\section{2 组织架构}

常见和有效的组织模式为组建跨部门指导委 员会或董事会作为倡议决策机构(印度、德国、加拿 大、澳大利亚、南非), 并下设秘书处(日本)或工作 组(印度、秘鲁)。工作组或主题组的设立通常基于 有明确需求的部门与行业, 且往往由政府和协会代 表牵头。

\section{3 成员加入}

(1)企业通过签署宣言、协议或谅解备忘录正式 加入倡议(加拿大、秘鲁、印度、德国), 并承诺定期 发布进展报告。部分国家(德国、南非)还开发了信 息披露指标用于支持企业披露信息。

(2)倡议所针对的企业类型多样。各国倡议通常 对加入的企业没有行业类别或规模限制。有的倡议 服务数量众多的制造业中小企业(德国、印度)，有的 则专注大公司(日本)。多数倡议偏重国内某些特定 行业如韩国(生物技术和遗传资源利用)、澳大利亚 (银行业)、南非(采掘业)。

(3)机构会员的加入往往可带动大量企业参与。 这些机构包括：行业协会(印度工业联合会)、商会 和基金会等。

(4)少数倡议(日本、南非)对成员进行分级：正 式成员、一般成员和准成员。

\section{4 服务平台}

(1)各国倡议为企业提供的服务各有特色，一 般包括法律与政策解读、信息分享、知识传播和培 训研讨会。另外，有些侧重技术工具开发与应用(日 本、德国、印度)，有些则侧重建立部门对话机制，促 进行业规划纳入。生态系统服务价值作为自然资本 的价值研究，以及企业对生物多样性的依赖与影响 的评价已成为国际趋势。目前, 多国倡议已开展此 类工作。总体上，各国倡议机制在服务体系和平台 构建方面进展不一, 但为规避运营风险、加强品牌 和美誉度并为《联合国可持续发展2030议程》做出 贡献，推进企业参与生物多样性已成为各国共识。

(2)倡议多通过指引、指南和标准引导企业参 与。秘鲁倡议是由环境部直接管理, 已发布了《生 物多样性与生态系统服务共同投资的政策指引》; 加拿大倡议制定了《企业与生物多样性保护指南》, 
为在商业规划、运营和决策中纳入相关议题提供指 导和建议; 日本倡议则开发了森林和水资源自愿性 标准。

\section{5 资金平衡}

除了政府支持, 成员缴纳会费(日本、加拿大) 也是各国倡议的主要固定收入来源。而其他不固定 收入模式包括实物捐赠、项目资金捐赠、志愿服务 等, 其中利用与《公约》和本国政府的关系, 与有 特定需求的企业联合、设计和管理公共-私营部门 伙伴关系(PPP)项目是多数倡议实现收益的重要途 径。各国都强调要基于本国实情, 采取灵活多变的 策略。

\section{6 未来挑战}

(1)获得企业更高优先性。如日本指出：参加倡 议的成员多是企业中层经理作为代表，而不是公司 首席执行官和高层决策者。生物多样性倡议如何获 得企业更高优先性是挑战也是机遇。

(2)各国倡议间合作。目前只有少数倡议之间实 现了合作(德国与印度)。最近, 《公约》秘书处增加 了一名专职人员, GPBB下近 20 个国家倡议之间的 交流、协调在未来有望得到加强(庄国泰等, 2013)

(3)企业社会责任(Corporate Social Responsibility, CSR)专业机构作用日益重要。由于有的倡议是 由本土的CSR专业机构成立和运行(澳大利亚SBA), 因此, CSR对促进企业参与的拉动和推动作用日益 强大。这与欧盟敦促成员国制定《企业社会责任国 家行动计划》(NAPs on CSR)和2014年欧洲议会通 过《非财务信息披露指令》(Directive on Non-financial Information Disclosure)等议程推动有关。

\section{7 主要启示}

(1)根据论坛会议沟通和实际工作交流，大量 企业表现出参与生物多样性伙伴关系倡议的积极 意愿。生物多样性维系着人类经济、生计和福祉已 成为社会共识, 这已使企业将参与生物多样性保护 从单一的环境和社会责任议题，提升为战略资源、 运营层面的可持续发展主题。在责任投资、绿色供 应链、可持续消费等国内外倡议、标准和指引纳入 生态系统服务指标, 以及认证认可、特许经营、许 可证和配额等的潜在风险与机会, 增强了企业保护 生物多样性的意愿。

(2)推动企业参与的国际资源网络已基本建立。 GPBB不仅是组织和宣传平台, 还是资源体系, 为
各国倡议行动提供了国际最新研究成果、方法学、 工具、自愿性贡献评价标准、简报、案例和数据库, 并开展一系列活动来促进各国参与、贡献和受益。

(3)受限于规模和资金, 绝大多数企业的参与 需要本国政府更为有力的引导和支持。各国企业倡 议行动为企业参与GPBB的鸿沟架起了桥梁, 我国 应借鉴他国经验, 研究、吸收和引进国际资源, 服 务于本国企业服务平台的搭建。

\section{中国推动GPBB的相关情况及问题}

中国是《公约》的首批签约国之一。2010年，国 务院审议通过了《中国生物多样性保护战略与行动 计划(2011-2030年)》, 明确了中国生物多样性保护 的战略目标、战略任务和具体任务。该计划提出, 要 “推动建立生物多样性保护伙伴关系”, “研究建立社 会各方参与的保护联盟”。2015年, 中国正式加入 GPBB。中国推动GPBB的机制为CBBP倡议。截至 目前, 虽然中国已开展了许多推动 $\mathrm{CBBP}$ 的相关工 作, 但仍然存在和面临许多问题与挑战(张风春等, 2014)。

首先, 由于中国倡议 CBBP相关文件仍未通过 审批, 因此, 尽管根据前期调研和会议论坛沟通已 知许多企业非常有意愿成为中国伙伴关系成员单 位, 但仍无章可循, 无法加入。这也导致有相当一 批企业和组织继续保持观望态度。

其次, 相对于前文介绍的国家, 中国尚未建立 健全推动CBBP倡议行动的组织模式和资金机制(张 风春等, 2015)。中国在组织模式和资金机制设计、 方案报批等方面亟待加快进度, 力争早日获得政府 有关部门更多支持，包括：实物捐赠、购买服务、 网站宣传、促进行业协会合作、资金支持等。

最后, 《公约》第15次缔约方大会将于2020年 在北京召开。这对组织本次大会的东道国而言, 在 促进CBBP的管理运行方面提出了更高和更为紧迫 的要求。

\section{中国未来推进GPBB的政策建议}

建议中国未来推进GPBB倡议可实施“两步走” 战略。

\section{1 成立并发起CBBP联盟倡议}

一是结合各国倡议的经验, 科学设计搭建和健 全符合中国国情的倡议组织机制。组建跨部门的指 
导委员会作为决策机构, 纳入国内外重要组织、行 业协会等合作伙伴，促进企业成员批量加入和资源 整合。二是结合国际经验, 积极设计符合中国国情 的多种渠道资金支持机制。除争取政府支持外，可 探索成员缴纳会费作为固定收入来源, 其他作为不 固定的辅助收入的资金支持模式。三是尽快起草联 盟《章程》和相关启动文件, 启动联盟并加强组织 管理。

\section{2 加大国际公约建设和国家履约谈判支持}

一是积极参与GPBB主席国、执行委员会和工 作组相关工作。二是适时推荐国内专家和企业, 支 持《公约》秘书处正在进行的重要方法学、工具开 发与项目示范。三是加强国内相关部门代表、产业 专家与有关部委的沟通, 在关联性强的产业积累数 据, 支撑履约谈判。四是鼓励、支持国内企业、组 织在缔约方大会上宣传成功故事, 协调统一行动, 做强中国展团。五是支持在2020年北京第十五次 《公约》缔约方大会上由中国编制并发布2020-2030 年企业参与全球纲领性文件, 并为全球企业贡献联合 国可持续发展目标(SDG)设计可操作的技术路线图。

\section{参考文献}

Wang AH, Wu JY, Liu JX (2015) Business and biodiversity: A review of the negotiation progress of a new issue under the Convention on Biological Diversity. Biodiversity Science, 23, 689-694. (in Chinese with English abstract) [王爱华, 武建勇, 刘纪新 (2015) 企业与生物多样性: 《生物多样 性公约》新议题的产生与谈判进展. 生物多样性, 23, 689-694.]

Zhang FC, Fang J, Yin GF (2014) Enterprises' participation in biodiversity: Question, situation and approach. China WTO Tribune, (11), 71-75. (in Chinese) [张风春, 方菁, 殷格非 (2014) 企业参与生物多样性的问题、现状与路径. WTO 经济导刊, (11), 71-75.]

Zhang FC, Liu WH (2015) Multi-stakeholder engaging mechanism for biodiversity conservation in China. Environmental Protection, (5), 29-33. (in Chinese) [张风春, 刘文慧 (2015) 生物多样性保护多方利益相关者参与现 状与机制构建研究. 环境保护, (5), 29-33.]

Zhuang GT, Shen HB (2013) Biodiversity conservation: New problems and challenges. World Environment, (4), 16-21. (in Chinese) [庄国泰, 沈海滨 (2013) 生物多样性保护面 临的新问题和新挑战. 世界环境, (4), 16-21.]

(责任编委: 薛达元 责任编辑: 时意专) 